\title{
Air pollution and emergency hospital admissions for cardiovascular diseases in Valencia, Spain
}

\author{
F Ballester, J M Tenías, S Pérez-Hoyos
}

\begin{abstract}
Study objective-To estimate the shortterm association between air pollution levels and emergency hospital admissions for cardiovascular diseases in Valencia, within 1994-1996 period.

Design-Daily levels of air pollution and emergency admissions for cardiovascular diseases were related to using an ecological time series design. The number of admissions was obtained from the hospital records database. Selected groups of causes were all cardiovascular diseases, heart admissions, and admissions for cerebrovascular diseases. The number of admissions for digestive diseases was used as control. Pollutants were black smoke, sulphur dioxide $\left(\mathrm{SO}_{2}\right)$, nitrogen dioxide $\left(\mathrm{NO}_{2}\right)$, carbon monoxide $(\mathrm{CO})$ and ozone $\left(\mathrm{O}_{3}\right)$. Magnitude of association was estimated by Poisson autoregresive regression. Estimations were calculated according the hottest (May to October) and the coldest (November to April) periods.
\end{abstract}

Setting-City of Valencia, Spain, about 750000 inhabitants.

Participants-People being admitted to the two major hospitals in the city, with a catchment area of nearly 400000 inhabitants.

Main results-For the whole period, a significant association for $\mathrm{SO}_{2}-24 \mathrm{~h}$ was found so a rise in its levels of $10 \mu \mathrm{g} / \mathrm{m}^{3}$ was associated with an increment of $3 \%$ $(95 \% \mathrm{CI} 0.4$ to $5.7 \%)$ in the expected number of cardiovascular admissions. A significant association for black smoke, $\mathrm{SO}_{2}-24 \mathrm{~h}, \mathrm{SO}_{2}-1 \mathrm{~h}$, and $\mathrm{CO}-1 \mathrm{~h}$ was found in the hottest semester. All these associations were verified with a lag of two days. The estimates of the associations for particles, $\mathrm{SO}_{2}$, and $\mathrm{CO}$ were affected by the inclusion of the other pollutants in their models. $\mathrm{NO}_{2}$ was independently associated with cerebrovascular admissions. There were no significant associations between air pollution and admissions for digestive diseases.

Conclusions-Current levels of air pollution and emergency cardiovascular admissions are significantly related in Valencia.

(F Epidemiol Community Health 2001;55:57-65)

Dr Ballester, Unit of

Epidemiology and Statistics,

Valencian School of Studies

for Health (EVES), C/Joan

de Garay 21, 46017 València,

Spain (ballester_fer@gva.es)

Accepted for publication 19 July 2000

The impact of air pollution on several outcomes (that is, mortality, respiratory diseases) has been studied in a considerable number of cities throughout the world. Studies on mor- tality impact of air pollution have shown an association with cardiovascular mortality, ${ }^{1-5}$ however the short-term relation between cardiovascular admissions and urban air pollution has not been assessed until a few years ago. Some studies have been carried out recently in this sense, especially in North America ${ }^{6-13}$ and also in some cities in northern or western Europe,${ }^{14-18}$ in Sydney, Australia, ${ }^{19}$ and in Hong Kong, China. ${ }^{20}$ In the Mediterranean area only one study, in Athens, ${ }^{21}$ has examined this relation.

Most of these time series studies showed an effect predominance of particulates and carbon monoxide (CO) on cardiovascular admissions. $^{6-1012131718}$ However, the results in some works in Europe $\mathrm{E}^{15}$ and in Sydney ${ }^{19}$ suggest an independent effect of the nitrogen dioxide $\left(\mathrm{NO}_{2}\right)$ and sulphur dioxide $\left(\mathrm{SO}_{2}\right)$. Furthermore, two of the studies in Canada showed a more consistent effect for sulphates ${ }^{7}$ or for ozone. ${ }^{11}$

Up to now the effect of air pollution on cardiovascular diseases morbidity has not been assessed in Spain, a country that has a mild climate, different to the climates of most of the other places studied. For this reason it seemed inadequate to extrapolate the results in other parts of the world to our particular environment. Moreover, it has been suggested that weather or, more particularly, temperature may modify the effects of air pollution on health, both high ${ }^{22}$ and low temperatures. ${ }^{12}$ Specifically, the results of the latter study, carried out in Chicago, USA suggest that the effect of CO on hospital admissions for heart failure may be temperature dependent, with the magnitude of the effect increasing with decreasing temperature. ${ }^{12}$ In this sense, laboratory and further epidemiological studies in other cities with different climates are claimed in order to validate that hypothesis. In this study we explore the short-term association between air pollution levels and emergency hospital admissions for cardiovascular diseases in a Mediterranean location, the city of Valencia, Spain, for the period 1994-1996.

\section{Methods}

The study was part of an ecological time series one, where daily levels of air pollution and emergency admissions for cardiovascular disease in the two main hospitals of the city of Valencia were related controlling for the major confounding variables.
Valencia is located on the Mediterranean coast and has a mesothermal climate (mild climate). The air pollution mainly derives from motor 
Table 1 Summary of the daily figures for the number of hospital admissions for cardiovascular and digestive causes, the concentrations of air pollutants, the meteorological variables and the flu incidence. Valencia, Spain (1994-1996)

\begin{tabular}{|c|c|c|c|c|c|c|c|}
\hline & \multicolumn{5}{|c|}{ Whole period } & \multicolumn{2}{|c|}{ Semesters } \\
\hline & Mean & Minimum & P50 & Maximum & $n$ & $\begin{array}{l}\text { hottest } \\
\text { Mean }\end{array}$ & $\begin{array}{l}\text { coldest } \\
\text { Mean }\end{array}$ \\
\hline Cardiovascular diseases & 7.0 & 0 & 7.0 & 20 & 1080 & 6.6 & 7.4 \\
\hline Heart diseases & 3.9 & 0 & 4.0 & 13 & 1080 & 3.7 & 4.2 \\
\hline Cerebrovascular diseases & 1.5 & 0 & 1 & 7 & 1080 & 1.5 & 1.6 \\
\hline Digestive diseases & 5.6 & 1 & 5 & 15 & 1076 & 5.7 & 5.5 \\
\hline Mean temperature $\left({ }^{\circ} \mathrm{C}\right)$ & 18.7 & 6.6 & 18.4 & 33.8 & 1080 & 22.9 & 14.4 \\
\hline Relative humidity (\%) & 63.1 & 23.0 & 65.0 & 96.0 & 1080 & 65.3 & 60.7 \\
\hline Black smoke $24 \mathrm{~h}\left(\mu \mathrm{g} / \mathrm{m}^{3}\right)$ & 43.7 & 8.0 & 40.4 & 136.2 & 1080 & 37.2 & 50.7 \\
\hline $\mathrm{SO}_{2} 24 \mathrm{~h}\left(\mu \mathrm{g} / \mathrm{m}^{3}\right)$ & 25.6 & 4.4 & 25.0 & 68.4 & 1073 & 21.6 & 29.8 \\
\hline $\mathrm{NO}_{2} 24 \mathrm{~h}\left(\mu \mathrm{g} / \mathrm{m}^{3}\right)$ & 66.8 & 11.9 & 64.7 & 155.1 & 1072 & 66.8 & 66.9 \\
\hline $\mathrm{NO}_{2} 1 \mathrm{~h}\left(\mu \mathrm{g} / \mathrm{m}^{3}\right)$ & 116.1 & 31.1 & 113.2 & 469.0 & 1072 & 116.3 & 116.0 \\
\hline $\mathrm{O}_{3} 8 \mathrm{~h}\left(\mu \mathrm{g} / \mathrm{m}^{3}\right)$ & 45.9 & 10.2 & 45.0 & 125.0 & 1071 & 54.2 & 37.2 \\
\hline $\mathrm{CO} 1 \mathrm{~h}\left(\mathrm{mg} / \mathrm{m}^{3}\right)$ & 6.2 & 0.6 & 5.7 & 17.8 & 1078 & 5.1 & 7.4 \\
\hline Cases of influenza & 167.5 & 3.0 & 120.0 & 660.0 & 1080 & 68.6 & 270.9 \\
\hline
\end{tabular}

$\mathrm{n}$ : number of days with valid observations.

vehicle exhaust emissions, with industrial pollution playing a smaller part. The analysis took place in the Hospital Clínico Universitario, and Hospital Universitario La Fe. These hospitals have an urban catchment area of 376681 inhabitants (total population of the city 750000 inhabitants). Because both hospitals are part of the public health service
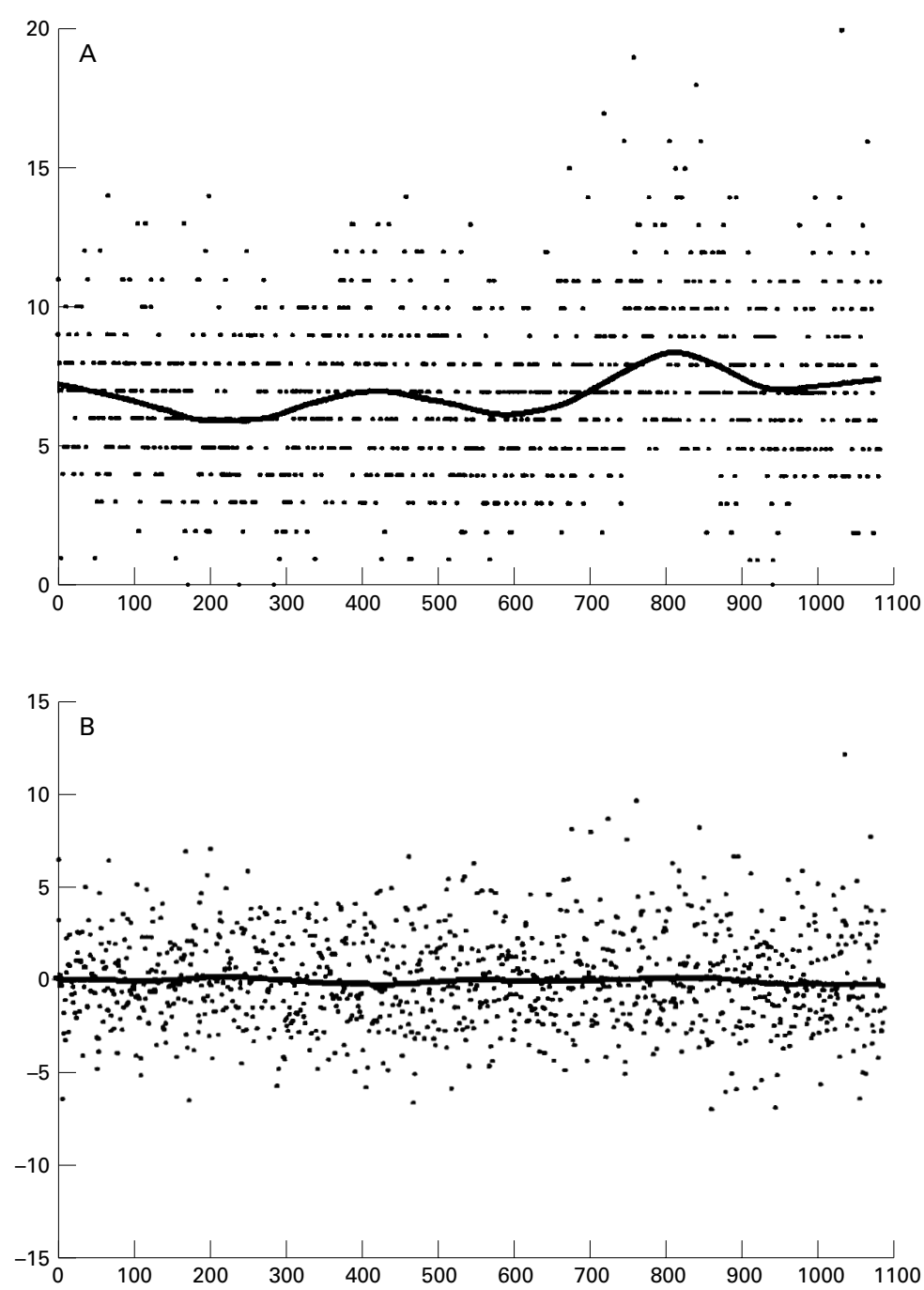

Figure 1 Raw (A) and residual after adjusting for the core model (B) series of the daily number of admissions for cardiovascular diseases in Valencia (1994-1996). Adjusted line: loess with a width of $20 \%$. network, access to emergency health services is universal. In a previous study we found that people attending a different hospital emergency department for respiratory diseases to their reference one in Valencia represented less than 3\% (unpublished data).

DATA

Health measures

The number of daily admissions was obtained from the registry databases of the two hospitals, being selected the admissions for residents of Valencia city with a primary discharge diagnosis of the following causes (codes of International Classification of Diseases, 9th revision, ICD-9): cardiovascular diseases (ICD-9: 390-459); heart diseases (ICD-9: 410-414, 427, 428); cerebrovascular diseases (ICD 9: 430-438); and admissions for digestive disease excluding vascular related ones (ICD 9: 530-534,5 40-543, 560-569, 571$572,574-578)$. The latter was selected as a control series. We preferred the use of broad categories rather than more specific ones in order to obtain more precision in results ${ }^{13}$ and seeking to reduce likelihood of misclassification. ${ }^{19}$

\section{Exposure data}

The pollution data were obtained from the city's air pollution monitoring network, which consists of 14 manual and five automatic monitoring stations. From the manual network the 24 hour average levels for black smoke (reflectometry method) were obtained and from the automatic network the 24 hour average and the one hour maximum levels for $\mathrm{NO}_{2}$ (chemiluminescence), $\mathrm{SO}_{2}$ (ultraviolet fluorescence) and CO (infrared absorption) as well as the eight hours moving average and the one hour maximum levels for ozone (UV absorption). Only the data obtained from those stations with valid readings on more than $75 \%$ of days were used in this investigation. The results of this calculation were ruled out if less than $75 \%$ of data for that day was available. Using these criteria, seven manual and the five automatic monitoring stations were finally selected. The correlation between the measurements at different stations varied from 0.30 to 0.62 in the manual network (that is, black 
Table 2 Pearson correlation coefficients among the environmental variables. Valencia, 1994-1996

\begin{tabular}{|c|c|c|c|c|c|c|c|}
\hline Variable & Temperature & Humidity & Black smoke & $\mathrm{SO}_{2} 24 h$ & $\mathrm{NO}_{2} 1 \mathrm{~h}$ & CO $24 h$ & $\mathrm{O}_{3} 8 \mathrm{~h}$ \\
\hline Temperature & 1 & 0.07 & -0.41 & -0.42 & -0.10 & -0.55 & 0.45 \\
\hline Humidity & & 1 & 0.07 & -0.18 & -0.10 & $-0.02^{\star}$ & -0.10 \\
\hline Black smoke & & & 1 & 0.63 & 0.33 & 0.64 & -0.57 \\
\hline $\mathrm{SO}_{2} 24 \mathrm{~h}$ & & & & 1 & 0.22 & 0.74 & -0.35 \\
\hline $\mathrm{NO}_{2} 1 \mathrm{~h}$ & & & & & 1 & $0.03^{\star}$ & -0.26 \\
\hline $\mathrm{CO} 24 \mathrm{~h}$ & & & & & & 1 & -0.42 \\
\hline $\mathrm{O}_{3} 8 \mathrm{~h}$ & & & & & & & 1 \\
\hline
\end{tabular}

$24 \mathrm{~h}$ daily average; $1 \mathrm{~h}$ : daily one hour maximum level; $8 \mathrm{~h}$ daily eight hours moving average maximum level. ${ }^{\star} \mathrm{p}>0.05$.

smoke), and from 0.46 to 0.78 in the automatic one (gaseous pollutants).

Data of control variables

The daily data for temperature and relative humidity were obtained from Valencia's meteorological station, located within an urban garden. The weekly influenza cases were taken from the registers of notified diseases. Local holidays and the period of strike action by medical staff during May 1995 were also taken into consideration.

ANALYSIS

Magnitude of association was estimated by Poisson autoregresive regression following the standardised methodology of the APHEA project ${ }^{23-25}$ with some modifications introduced in the Spanish EMECAM project. ${ }^{26}{ }^{27}$ With this approach we assume counts of daily admissions follow a non-stationary overdispersed Poisson process where variations could be explained in part for some factors varying in time (that is, long term trend and seasonality, temperature and humidity, week days, flu incidence, special events, or air pollution). The effect of the former variables must be taken into account to avoid confusion in the estimation of the relation between admissions and air pollution. Therefore, using Poisson regression we analysed data in two steps. Firstly, a core model was built for each outcome variable (that is, the series of daily admissions) controlling for the main confounding variables Secondly, the association with air pollutants was estimated examining the delayed relation up to the fifth lag of pollutants. To control residual overdispersion serial autocorrelation in the final models autoregressive terms up to the fifth order were checked, including them in the model when significant.

The relation between air pollutants and admissions does not have to be linear. Therefore, besides the linear model, a nonparametric model, including a loess term for the pollutant, has been fitted. This kind of model does not assume any shape of the relation. The depart from the linearity was checked comparing the deviance of both models by means of a $\chi^{2}$ test with the difference of degree of freedoms between the models.

Furthermore, estimations were calculated for the hottest (May to October) and coldest (November to April) semester. Lastly, to analyse the independence of the associations, two pollutant models were also fitted. The effect of pollution was calculated using the relative risk (RR) corresponding to an increase in $10 \mu \mathrm{g} / \mathrm{m}^{3}$ in air pollutant indicators $\left(1 \mathrm{mg} / \mathrm{m}^{3}\right.$ for $\mathrm{CO}$ ).

\section{Results}

Table 1 shows the summary statistics of the health and environmental data in Valencia. The mean daily number of cardiovascular admissions was seven, most of them attributable to heart diseases (3.9), and to cerebrovascular diseases (1.5). These figures would correspond to a daily rate of $18.6,10.4$, and 4 , respectively, for a hypothetical population of one million inhabitants.

Levels of pollutants are, in general, moderate. However, if we examine them in the light of the recent European Directive relating on limit values for some pollutants ${ }^{28}$ it would be difficult to meet some of them, especially for $\mathrm{NO}_{2}$ (limit value for the annual mean of $\mathrm{NO}_{2}: 40 \mu \mathrm{g} / \mathrm{m}^{3}$ ).

The cardiovascular admissions series presented a seasonal trend with higher numbers in the coldest months. This pattern was removed after adjusting for the control variables (fig 1). Black smoke, $\mathrm{SO}_{2}$, and $\mathrm{CO}$ showed the same seasonal pattern as cardiovascular admissions, and high correlation among them (table 2). Ozone presented positive correlation with temperature and negative correlation with the other pollutants. Nitrogen dioxide did not show a clear pattern.

Table 3 shows the estimates for the association between air pollutants and the three groups of emergency cardiovascular admissions for the whole period. A significant association was found for $\mathrm{SO}_{2} 24 \mathrm{~h}$, lag 2, so that a rise in its levels of $10 \mu \mathrm{g} / \mathrm{m}^{3}$ was associated with an increment of $3.0 \% \quad(95 \%$ confidence intervals, (95\% CI 0.4 to $5.7 \%$ ) and $3.6 \%$

Table 3 Association between air pollution and the number of emergency hospital admissions for the three groups of cardiovascular diseases and the one of digestive admissions. Valencia 1994-1996. Results expressed as the relative risk (and the 95\%CI) in admissions for an increase in the pollutant levels of 10 $\mu \mathrm{g} / \mathrm{m}^{3}$ ( $1 \mathrm{mg} / \mathrm{m}^{3}$ for $\left.\mathrm{CO}\right)$

\begin{tabular}{|c|c|c|c|c|c|c|c|c|}
\hline Pollutants & All cardiovascular diseases & $L$ & Heart diseases & $L$ & Cerebrovascular diseases & $L$ & Digestive diseases & $L$ \\
\hline Black smoke & $1.0145(0.9996 ; 1.0297)$ & 2 & $1.0149(0.9953 ; 1.0349)$ & 2 & $1.0156(0.9860 ; 1.0461)$ & 5 & $0.9905(0.9750 ; 1.0063)$ & 3 \\
\hline $\mathrm{SO}_{2} 24 \mathrm{~h}$ & $1.0302(1.0042 ; 1.0568)$ & 2 & $1.0357(1.0012 ; 1.0714)$ & 2 & $1.0378(0.9844 ; 1.0940)$ & 5 & $1.0234(0.9958 ; 1.0518)$ & 1 \\
\hline $\mathrm{NO}_{2} 1 \mathrm{~h}$ & $1.0065(0.9982 ; 1.0148)$ & 0 & $1.0085(0.9984 ; 1.0188)$ & 2 & $1.0362^{\star}(1.0066 ; 1.0667)$ & 4 & $0.9970(0.9909 ; 1.0031)$ & 2 \\
\hline $\mathrm{O}_{3} 8 \mathrm{~h}$ & $0.9905(0.9710 ; 1.0104)$ & 2 & $0.9786(0.9535 ; 1.0044)$ & 5 & $0.9760(0.9464 ; 1.0066)$ & 2 & $1.0051(0.9896 ; 1.0210)$ & 4 \\
\hline $\mathrm{CO} 1 \mathrm{~h}$ & $1.0077(0.9912 ; 1.0138)$ & 2 & $1.0092(0.9945 ; 1.0242)$ & 1 & $0.9874(0.9646 ; 1.0107)$ & 1 & $0.9937(0.9823 ; 1.0052)$ & 3 \\
\hline
\end{tabular}

L: lag with the best fit. ${ }^{\star} \mathrm{NO}_{2}-24 \mathrm{~h}$. 

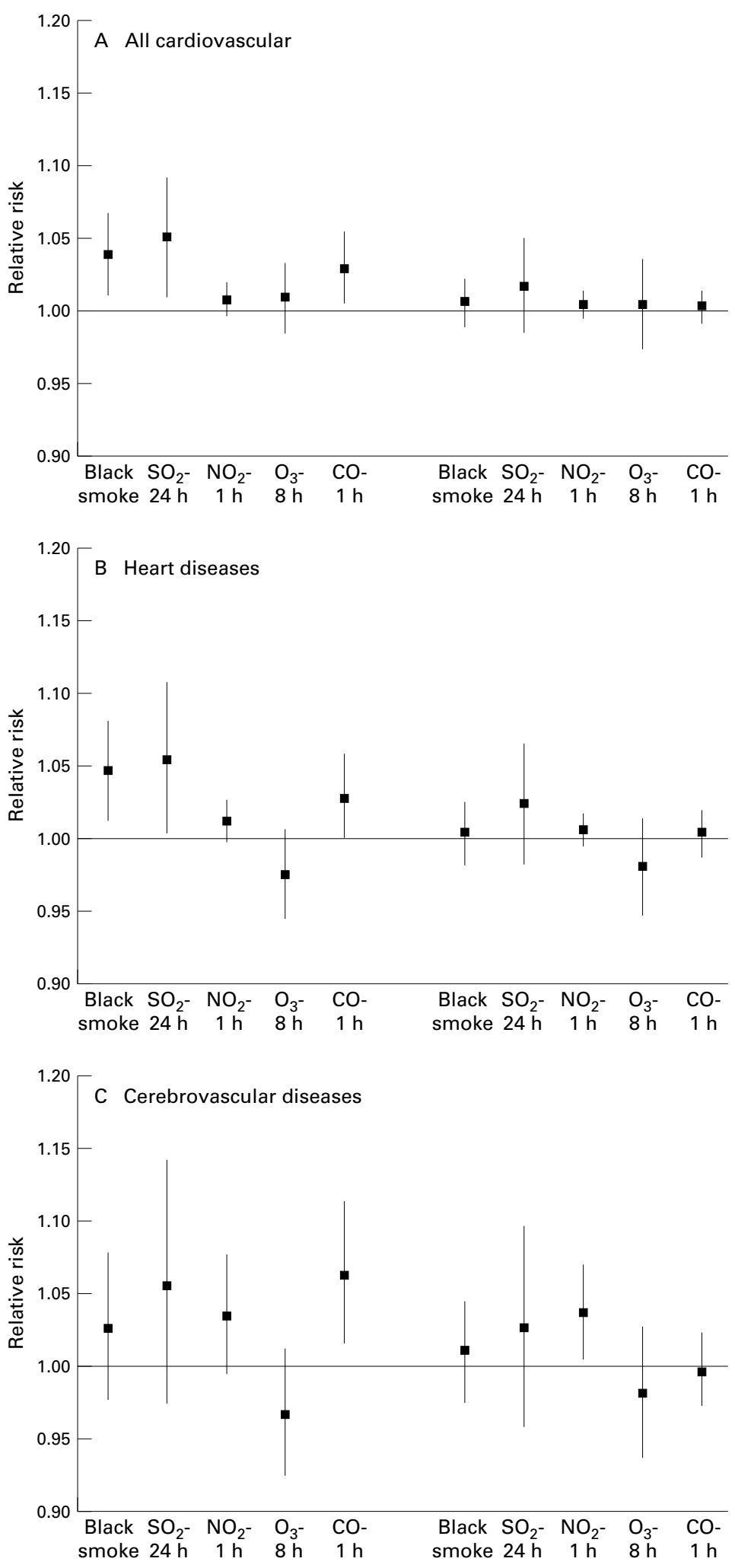

Hot semester

Cold semester

Figure 2 Association between air pollution and the number of emergency admissions for selected causes of cardiovascular diseases. Analysis for semesters. Valencia (1994-1996). Hot semester: May; October. Cold Semester: November; April. (A) All cardiovascular disease admissions; (B) heart disease admissions; and (C) cerebrovascular disease admissions. Results expressed as the relative risk (and the 95\% CI) in admissions for an increase in the pollutant levels of $10 \mu \mathrm{g} / \mathrm{m}^{3}$ (1 $\mathrm{mg} / \mathrm{m}^{3}$ for $\left.\mathrm{CO}\right)$.

(95\% CI 0.1 to $7.1 \%)$ in the expected number of all cardiovascular and heart diseases admissions, respectively. A similar increase in $\mathrm{NO}_{2}$
$24 \mathrm{~h}$, lag 4 , was associated with an increment of $3.6 \%(95 \%$ CI 0.7 to $6.7 \%)$ in the expected number of admissions for cerebrovascular diseases. There were no significant associations between air pollution and admissions for digestive diseases. On the other hand, the fit of the model did not change significantly after including the air pollutant indicators in a nonparametric way. In that sense the estimated models conducted to assume the linear relation between air pollution indicators and hospital admissions.

As shown in figure 2, in the analysis for semesters some effect modifications were verified. Thus, the association of cardiovascular admissions with black smoke, $\mathrm{SO}_{2}$, and $\mathrm{CO}$ was higher in the hottest semester. For the group of all cardiovascular admissions (fig 2A) a significant association for black smoke (RR $10 \mu \mathrm{g} / \mathrm{m}^{3}$ : $1.038 ; 95 \%$ CI 1.011 to 1.067 ) was found in the hottest semester. It was also found for $\mathrm{SO}_{2}$ $24 \mathrm{~h}$ (RR $10 \mu \mathrm{g} / \mathrm{m}^{3}$ : 1.050; 95\%CI 1.010 to 1.092), for $\mathrm{SO}_{2} 1 \mathrm{~h}\left(\mathrm{RR} 10 \mu \mathrm{g} / \mathrm{m}^{3}\right.$ : 1.017; $95 \% \mathrm{CI} 1.002$ to 1.032$)$, and for CO $1 \mathrm{~h}$ (RR 1 $\mathrm{mg} / \mathrm{m}^{3}$ : $1.029 ; 95 \% \mathrm{CI} 1.005$ to 1.055$)$. All these estimates were verified for a lag of two days. No significant association was found in the coldest semester. A similar pattern was observed for heart disease admissions (fig 2B). That is to say, significant associations were found in the hottest semester for black smoke (RR $10 \mu \mathrm{g} / \mathrm{m}^{3}: 1.047 ; 95 \%$ CI 1.013 to 1.028 ), for $\mathrm{SO}_{2} 24 \mathrm{~h}\left(\mathrm{RR} 10 \mu \mathrm{g} / \mathrm{m}^{3}: 1.054 ; 95 \% \mathrm{CI}\right.$ 1.003 to 1.107 ), and for CO $1 \mathrm{~h}$ (RR $1 \mathrm{mg} / \mathrm{m}^{3}$ : 1.029 ; $95 \%$ CI 1.000 to 1.058 ). Lastly, admissions for cerebrovascular diseases presented some different results (fig 2C). The most consistent association was with $\mathrm{NO}_{2} 24 \mathrm{~h}$ at lag 4, with significance in the coldest semester (RR $10 \mu \mathrm{g} / \mathrm{m}^{3}: 1.037 ; 95 \%$ CI 1.005 to 1.070$)$ and quite similar estimates in the hottest one (RR $10 \mu \mathrm{g} / \mathrm{m}^{3}: 1.034 ; 95 \%$ CI 0.993 to 1.077$)$. The only significant relation in the hot semester was for CO $1 \mathrm{~h}$ (RR $1 \mathrm{mg} / \mathrm{m} 3: 1.064 ; 95 \% \mathrm{CI}$ 1.015 to 1.114$)$.

Regarding the two pollutant models they provide changes in some estimates. As can be seen in figure 3 ( $\mathrm{A}$ and $\mathrm{B}$ ) the estimations of $\mathrm{CO}$ and black smoke associations with admissions for all cardiovascular diseases and for hearth disease, respectively, were modified after the inclusion of $\mathrm{SO}_{2}$ in their models. The association of $\mathrm{NO}_{2}$ with admissions for cerebrovascular disease (fig 3C) did not change after controlling for other pollutants. In the stratified analysis by semesters, the two pollutant models yielded a similar pattern to the one provided for the whole period.

\section{Discussion}

To our knowledge, this is the first study on the short-term relation between air pollution and emergency hospital admissions for cardiovascular diseases in a Spanish city. Our results suggest that current levels of air pollution and emergency cardiovascular admissions are positive and significantly related in the city of Valencia. Four of the five pollutants studied presented a statistical significant association with cardiovascular admissions. Both black 

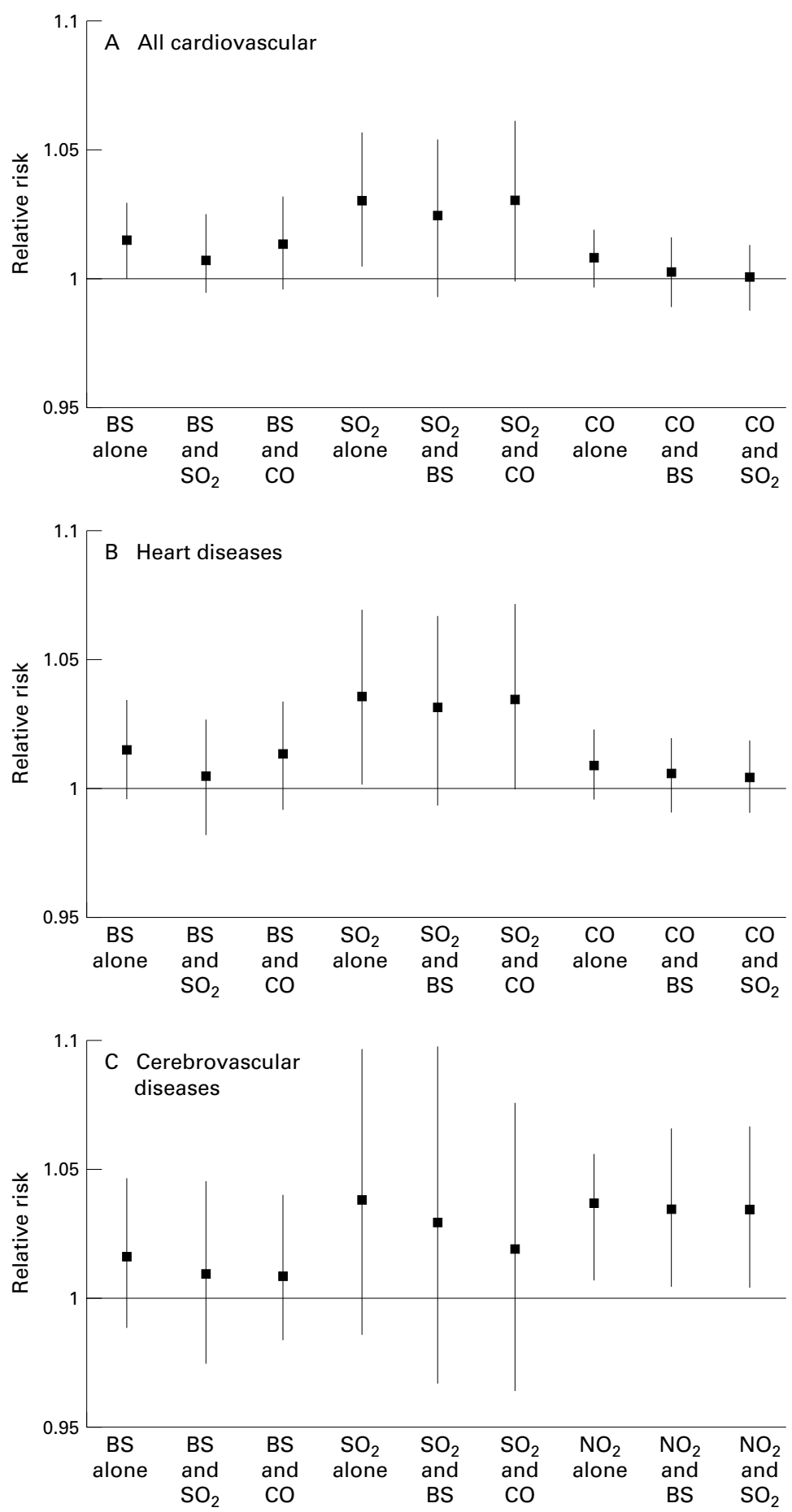

Figure 3 Association between air pollution and the number of emergency admissions for selected causes of cardiovascular diseases. Two pollutant models. Valencia (1994-1996): (A) all cardiovascular disease admissions; (B) heart disease admissions; and $(C)$ cerebrovascular disease admissions. Results expressed as the relative risk (and the 95\% CI) in admissions for an increase in the pollutant levels of $10 \mu \mathrm{g} / \mathrm{m}^{3}$ (1 $\mathrm{mg} / \mathrm{m}^{3}$ for CO).

smoke and $\mathrm{SO}_{2}$ were more specifically related with heart disease admissions. $\mathrm{NO}_{2}$ showed a clearer association with cerebrovascular disease, and $\mathrm{CO}$ was related with both groups of cardiovascular diseases. The associations with black smoke and $\mathrm{CO}$ were significant only for the hottest months. Because of the high correlation between three of the pollutants studied (black smoke, $\mathrm{CO}, \mathrm{SO}_{2}$ ), it is difficult to assign the potential causal role to an isolated pollut- ant. Lastly, ozone did not present any significant association with the outcomes.

Particulates (such as PM10, black smoke or other indicators), $\mathrm{CO}$ and $\mathrm{SO}_{2}$ are among the pollutants that have been most studied in relation to their cardiovascular impact. Attention has been especially paid to the possibility that the association found among some of these pollutants with cardiovascular admissions was independent of the other pollutants. In table 4 the main results of the revised papers including the same outcomes as our study are shown.

In the majority of studies carried out in North America, results show that $\mathrm{SO}_{2}$ does not seem to have an independent role in the association with admissions for cardiovascular diseases. Thus, Schwartz and Morris in a study in Detroit, USA, ${ }^{6}$ found an independent association of $\mathrm{PM}_{10}$ with daily admissions for ischaemic heart disease in people 65 years and older, and no independent contributions of $\mathrm{SO}_{2}, \mathrm{CO}$ and ozone for this outcome. $\mathrm{CO}$, as particles, presented an independent association with heart failure admissions. Similarly, in Tucson, USA, where the correlation between particles and $\mathrm{SO}_{2}$ was low $(r=0.095) \mathrm{Schwartz}^{10}$ showed an independent and additive association between both $\mathrm{PM}_{10}$ and $\mathrm{CO}$ with cardiovascular admissions in people over 65. Simultaneously, Burnett et al, in the 10 major Canadian cities, ${ }^{9}$ reported $\mathrm{CO}$ as the only gaseous pollutant independently associated with heart failure. In another study carried out by Burnett et al in Toronto, Canada, ${ }^{11}$ the apparent association between particles and cardiorespiratory hospitalisation disappeared after adjustment for $\mathrm{O}_{3}$, $\mathrm{NO}_{2}$ and $\mathrm{SO}_{2}$. In Chicago, USA, Morris and $\mathrm{Naumova}^{12}$ found a strong association of $\mathrm{CO}$ with congestive heart disease admissions in elderly people. Finally, Schwartz, in a study in eight US counties (including eastern and western ones) found independent effects (to weather or other pollutants) of $\mathrm{PM}_{10}$ and $\mathrm{CO}$ on hospital admissions for heart disease in people aged 65 and more. ${ }^{13}$

In contrast, results of the few studies carried out in Europe, are not so conclusive concerning the role of each pollutant. Thus, in London, Poloniecki et $a l^{17}$ found an association between $\mathrm{SO}_{2}$ and acute myocardial infarction and all circulatory diseases. For acute myocardial infarction they also obtained positive associations for black smoke, $\mathrm{CO}$, and $\mathrm{NO}_{2}$, but the most consistent results in the two pollutant models were for $\mathrm{SO}_{2}$. In Athens, Pantazopoulou et al did not include $\mathrm{SO}_{2}$ in their study arguing that its levels were low. In the Greek study the magnitude of the association for black smoke, $\mathrm{CO}$ and $\mathrm{NO}_{2}$ with cardiac admissions was of the same order as the one carried out in Valencia.

The results of the European study APHEA, ${ }^{5}$ have shown that $\mathrm{SO}_{2}$ together with the particles contribute to cardiovascular mortality. Furthermore, in this collaborative study, the summary estimates for cardiovascular mortality associated with $\mathrm{SO}_{2}$ were not substantially altered when particles were also included in the model, confirming that in the cities included in this study $\mathrm{SO}_{2}$ was more consistent 
Table 4 Results from articles studying the association between cardiovascular hospital admissions and air pollution

\begin{tabular}{|c|c|c|c|c|}
\hline Author/s (year of publication) & Site & Outcome & Pollutant & $\begin{array}{l}\text { Increase (\%) } \\
\text { in admissions * }\end{array}$ \\
\hline Schwartz $\mathrm{J}$ and Morris $\mathrm{R}^{6}$ & Detroit, USA & Ischaemic heart disease & PM10 & 0.6 \\
\hline Schwartz $\mathrm{J}^{10}$ & Tucson, USA & All cardiovascular & PM10 & 1.8 \\
\hline Burnett $\mathrm{R}$ et $a l^{11}$ & Toronto & Heart disease & Sulphates & 2.1 \\
\hline \multirow[t]{2}{*}{ Schwartz J ${ }^{13}$} & eight counties USA & All cardiovascular & PM10 & 1.0 \\
\hline & & & $\mathrm{CO}$ & 1.4 \\
\hline \multirow[t]{4}{*}{ Poloniecki JD et al ${ }^{16}$} & London, UK & All cardiovascular & BS & 1.6 \\
\hline & & & $\mathrm{SO}_{2}$ & 0.5 \\
\hline & & & $\mathrm{NO}_{2}$ & 0.4 \\
\hline & & & $\mathrm{CO}^{2}$ & 2.1 \\
\hline Wordley J et $a l^{17}$ & Birmingham, UK & All cardiovascular & PM10 & 2.1 \\
\hline \multirow[t]{2}{*}{ Morgan $\mathrm{G}$ et $a l^{19}$} & Sydney, Australia & Heart disease & PM10 & 0.8 \\
\hline & & & $\mathrm{NO}_{2}$ & 2.0 \\
\hline \multirow[t]{4}{*}{ Wong $\mathrm{T}$ et $a l^{0}$} & Hong Kong, China & All cardiovascular & PM10 & 0.6 \\
\hline & & & $\mathrm{SO}_{2}$ & 1.6 \\
\hline & & & $\mathrm{NO}_{2}$ & 1.3 \\
\hline & & & $\mathrm{O}_{3}$ & 1.3 \\
\hline
\end{tabular}

$\star$ Results expressed as the increase (\%) in admissions for an increase in the pollutant levels of $10 \mu \mathrm{g} / \mathrm{m}^{3}\left(1 \mathrm{mg} / \mathrm{m}^{3}\right.$ for CO). The results shown here are the significant results from single pollutant models.

than particles were. If $\mathrm{SO}_{2}$ has any impact on mortality through cardiovascular diseases, it is coherent to think that it can play a part in the triggering of cardiovascular disease. However, in previous studies carried out in Valencia, results have shown a clearer effect of particles on mortality than $\mathrm{SO}_{2},{ }^{29}{ }^{30}$ both in the all cause group of mortality and in the circulatory diseases one.

In this study, the two pollutant models showed the complex relation between the air pollution indicators and the outcomes studied. In fact, because of the high correlation between three of the pollutants studied (black smoke, $\left.\mathrm{CO}, \mathrm{SO}_{2}\right)$, it is difficult to assign the potential causal role to an isolated pollutant. Notwithstanding that, considering our results, the estimations of the association with cardiovascular diseases were a little more robust for $\mathrm{SO}_{2}$. All in all, it is possible that any of these three pollutants (or other elements that they may represent such as "proxy") may cause cardiovascular stress when reaching the cardiorespiratory system, increasing the probability of clinical symptoms. In this sense, provided the local characteristics of Valencia (high correlation between these three pollutants) any of them represents an indicator of a type of "mixture" of atmospheric pollution.

In general we found that the estimates for these three pollutants (black smoke, $\mathrm{SO}_{2}$, and $\mathrm{CO})$ were higher in the hottest semester than in the coldest one. We have found an effect modification for period on the relation between cardiovascular admissions and CO. Our estimates for $\mathrm{CO}$ are only significant for the hottest months.

Conversely, in their study in Chicago, Morris and Naumova ${ }^{12}$ found that the association of $\mathrm{CO}$ with congestive heart disease admissions was temperature dependent, with the magnitude of the effect increasing with decreasing temperature. There are some epidemiological evidence relating to an interaction between temperature and air pollution, both with low temperatures and high ones. In the study in Toronto, Burnett et al, ${ }^{11}$ described relatively weaker associations in summertime than in year round ones. They argued that it may be attributable to low summertime concentrations. This could not be the case in Valencia. In fact, the summer $\mathrm{CO}$ mean concentration in
Toronto was $2.1 \mathrm{mg} / \mathrm{ml}$, and the mean concentration in Valencia in the hottest semester was $5.1 \mathrm{mg} / \mathrm{ml}$. On the other hand, an interaction between air pollution and high temperatures in their relation with mortality was also described in the study in Athens. ${ }^{22}$

The results presented here are coherent with the findings of other studies carried out in Valencia on the short-term effect of air pollution on mortality. So, in the context of the Spanish multi-centred EMECAM Project ${ }^{26}$ the results for the association between $\mathrm{CO}$ and cardiovascular mortality in Valencia ${ }^{30}$ showed positive and significant estimates for the hottest months ( $R R$ for a $1 \mathrm{mg} / \mathrm{m}^{3}$ increase in the daily CO concentration of 1.068 ; 95\% CI: 1.007 to 1.133), which was not found during the rest of the year (RR $1 \mathrm{mg} / \mathrm{m}^{3}$ CO: 0.990; 95\% CI: 0.959 to 1.022 ). In a previous study we found the same pattern of effect modification for $\mathrm{SO}_{2}$ and total and cardiovascular mortality: its relation was significant in the hot period but not in the cold one. ${ }^{29}$

In some other Mediterranean cities the risk estimates for the relation between air pollution and mortality were higher in the warmer season. ${ }^{31}{ }^{32}$ Besides the potential for biological interaction between air pollution and mortality, other possible explanations have been argued. One derives from the fact that during the warmer months people could modify their activity patterns. ${ }^{33}$ This includes people spending more time outdoors and windows being left open for longer, so the actual exposure could be more correlated with outdoor concentrations. Another reason could be that, during the warmer period, other stronger determinants of daily mortality and morbidity (such as acute respiratory infections) are less influential. ${ }^{32}$ Lastly, one local potential reason for this pattern could be that the climate in Valencia is very mild, without extreme cold temperatures. In fact, the lowest daily average temperature registered during the study period $\left(6.6^{\circ} \mathrm{C}\right)$ was superior to the cut point for stratification corresponding to the lowest temperature strata analysed in Chicago $\left(4.4^{\circ} \mathrm{C}\right)$ for the daily maximum temperature. ${ }^{12}$ That is to say, it is difficult to have an interaction between air pollution and low extreme temperatures because they almost do not exist in Valencia. 
Our data provide some indication of an independent association between $\mathrm{NO}_{2}$ and hospitalisations for cerebrovascular disease. The correlation of $\mathrm{NO}_{2}$ with weather and other pollutants in Valencia is low, and daily level series of $\mathrm{NO}_{2}$ did not show a defined seasonal pattern. Furthermore, the estimates of that association did not change after adjusting for other pollutants. All this supports the idea that these results are not confounded for other factors varying in time

In contrast with cardiac disease, the relation between air pollution and cerebrovascular diseases has been explored in only a few studies. Pönka and Virtanen reported in Helsinki ${ }^{15}$ a similar relation between $\mathrm{NO}_{2}$ and cerebrovascular diseases than the one found in Valencia. In a study in Birmingham only including PM10 as air pollution indicator, Wordley et $a l^{17}$ showed an association of particulates with admissions for cerebrovascular diseases and not with other cardiovascular disease groupings. In another paper studying this diseases' group, Poloniecki et $a l^{16}$ did not find any evidence of its association with black smoke, ozone, $\mathrm{NO}_{2}, \mathrm{SO}_{2}$, or $\mathrm{CO}$, but it could be relevant to mention that these authors only explored the first lag of pollutants. In Hong Kong, China, Wong et al ${ }^{20}$ showed a significant relation of $\mathrm{NO}_{2}, \mathrm{O}_{3}, \mathrm{SO}_{2}$ and $\mathrm{PM}_{10}$ with hospital admissions for cardiovascular diseases. In their analysis for specific causes ischaemic heart disease and cerebrovascular diseases were not significantly associated with any of the pollutants; however $\mathrm{NO}_{2}$ showed the highest effect with cerebrovascular diseases $(\mathrm{RR}$ for an increase of $10 \mu \mathrm{g} / \mathrm{m}^{3}: 1.008,95 \%$ CI 0.998 to 1.018).

In a considerable number of studies, ozone has been linked with respiratory toxicity including increase of mortality, ${ }^{5}$ emergency respiratory visits, ${ }^{34}{ }^{35}$ and hospital admissions for respiratory morbidity. ${ }^{116}$ In Valencia we have described such a significant association with emergency visits for asthma ${ }^{37}$ and for chronic obstructive pulmonary disease. ${ }^{38}$ However, there is little evidence of an association between ozone and cardiovascular morbidity. Our results do not suggest an impact of ozone on the number of hospitalisations attributable to cardiovascular disease. These results agree with those obtained in other studies ${ }^{6} 810121619$ in that all of them did not find an association with cardiovascular hospital admissions. Only three of the studies reviewed showed evidence of a consistent association between ozone and cardiovascular admissions. In the study of Burnett et al in Toronto, ${ }^{11}$ ozone was the most clearly and strongly associated with hospitalisation for cardiac diseases in summer. In the study of Pönka and Virtanen in Helsinki, ${ }^{15}$ ozone, besides nitric oxide, was the most clearly associated pollutant with the number of emergent admissions for ischaemic cardiac diseases. Lastly, Wong et $a l^{20}$ in Hong Kong, found a significant relation of $\mathrm{O}_{3}$ with hospital admissions for cardiovascular diseases.

In contrast, Prescott $e t a l^{18}$ found a negative association of $\mathrm{O}_{3}$ with cardiovascular admissions in ages over 65 . The authors argued that,
KEY POINTS

- Current levels of air pollution and emergency cardiovascular admissions are significantly associated in Valencia.

- The independent effect of some correlated pollutants (that is, particles, $\mathrm{SO}_{2}$, and $\mathrm{CO}$ ) is difficult to evaluate, as they represent proxies of the quality of ambient air.

- $\mathrm{NO}_{2}$ could play a part in the development of cerebrovascular diseases; this hypothesis needs further investigation.

because of the complex relation between $\mathrm{O}_{3}$ and $\mathrm{NO}$ and $\mathrm{NO}_{2}$, their central estimate at the fixed sampling point could provide an inaccurate reflection of the actual exposure for most of the population. This fact may have happened in other cities where studies of the effect of ozone on health have been carried out. Because it is a secondary pollutant, generated from precursors such as nitrogen oxide and volatile organic compounds through exposure to solar radiation, it reaches its concentration maximum far from the emitting focus (mainly traffic). For that reason, to evaluate the impact of ozone on health more precisely, it would be suitable to have monitoring stations located in peripherical areas where the population is likely to be exposed to the highest levels of ozone. $^{39}$

In the past years a great advance has been made concerning the possible biological mechanism of the impairment of air pollution in cardiovascular health. Results of studies that have explored the possible physiopathological mechanisms have given evidence that fine particulates in suspension can lead to systemic effect, such as an increase of plasma viscosity ${ }^{40}$ or heartbeat alterations. ${ }^{41}$ Toxicological studies have found biological alterations in rats after exposure to filtered air or concentrated ambient particulate matter. ${ }^{42}$ Abnormalities in the electrocardiogram after exposure to fine particles have also been found in dogs. ${ }^{43}$

The possible role of CO in causing cardiovascular disease has been investigated for many years. ${ }^{44}$ People occupationally exposed to high levels of CO presented high risk of arteriosclerosis heart disease..$^{45}$ But even exposure to low doses of $\mathrm{CO}$ can produce significant effects on cardiac function during exercise in subjects with coronary artery disease, as showed by Allred et al. ${ }^{4647}$

The physiopathological mechanisms of $\mathrm{SO}_{2}$ and $\mathrm{NO}_{2}$ causing cardiovascular damages are insufficiently understood, and more research is needed in this way. Probably these pollutants, as also particles and $\mathrm{CO}$, could play a part among other not yet studied components of air pollution as sulphates or volatile organic aerosols from automotive or other sources.

The use of a database designed for other means may have a limited application in other different fields. In the case of time series epidemiological studies, the key aspects would be exhaustivity of registers, perseverance of specific clinical information and the fulfilment of 
date variable. ${ }^{48}$ The hospital database quality of Valencian Community has been analysed showing very few errors in the administration variables, except for the residence. ${ }^{48}$ This problem may result in a misclassification bias, which would be non-differential in any case, as it does not seem logical for patient residence data errors to be connected with daily atmospheric pollution levels. On the other hand, a study carried out in Canada ${ }^{49}$ showed a good agreement ( $\kappa$ index: 0.84 ) in the classification of visits attributable to heart disease, and there was no evidence of diagnostic bias in relation to daily air pollution levels.

In conclusion, these results add more evidence to the knowledge about the impact of air pollution on cardiovascular health, in this case in a Spanish Mediterranean city, a different climate to the ones already studied. Results show that an increase in pollution levels attributable to $\mathrm{SO}_{2}$, black smoke or $\mathrm{CO}$ are associated with an increase in the number of emergency admissions for heart diseases in Valencia. Furthermore, an association between environment levels of $\mathrm{NO}_{2}$ and the number of urgent admissions for cerebrovascular diseases has been found, although this aspect needs further investigation to enable adequate quantification. Moreover, the results presented here are coherent with previous studies on mortality carried out in Valencia. These evidences of preventable disease linked to air pollution must be a key element in the process of decision making related with public health policies.

The views exposed in this publication are those of the authors and not necessarily those of the funding institutions. We thank Rosa not necessarily those of the funding institutions. We thank Rosa Molina and Julián Gonzalez for their help dealing with data and for comments on the results. We acknowledge the help of Vicente
Escoms from the Information System of the Valencia Health Escoms from the Information System of the Valencia Health
Service in providing morbidity data, and Salvador Peiró and Service in providing morbidity data, and Salvador Peiró and
Julián Librero for assistance in obtaining the health outcomes Julián Librero for assistance in obtaining the health outcomes data. We are also grateful to the City of Valencia Environmental
Laboratory Service, and especially to José Luis Bosch and José Laboratory Service, and especially to José Luis Bosch and José Luis Pisón for their collaboration in providing air quality data. A previous version of this work was presented at the XV logical Association held in Florence in the summer of 1999.

Funding: this work was supported in part by a grant from the Conselleria de Sanitat. Generalitat Valenciana, project number $96 / 014$ and by a grant of Fondo Investigaciones Sanitarias, 96/014 and by a grant of Fondo Investigacione

Conflict of interest: none.

1 Schwartz J. What are people dying of on high air pollution days? Environ Res 1994;64:26-35.

$2 \mathrm{Xu}$ X, Gao J, Dockery D, et al. Air pollution and daily mortality in residential areas of Beijing, China. Arch Environ Health 1994;49:216-22.

3 Schwartz J. Total suspended particulate matter and daily mortality in Cincinnati, Ohio. Environ Health Perspect 1994;102:186-9.

4 Kelsall J, Samet J, Zeger S, et al. Air pollution and mortality in Philadelphia, 1974-1988. Am 7 Epidemiol 1997;146: $750-62$.

5 Zmirou D, Schwartz J, Saez M, et al. Time-series analysis of air pollution and cause-specific mortality. Epidemiology 1998;9:495-503

6 Schwartz J, Morris R. Air pollution and hospital admissions for cardiovascular disease in Detroit, Michigan. Am $\mathcal{F} E p i$ demiol 1995;142:23-35.

7 Burnett R, Dales R, Krewski D, et al. Associations between ambient particulate sulfate and admissions to Ontario hospitals for cardiac and respiratory diseases. Am $\mathcal{F}$ Epidemio 1995;142:15-22.

8 Morris R, Naumova E, Munasinghe R. Ambient Air Pollution and Hospitalization for Congestive Heart Failure among Elderly People in Seven Large US Cities. Am f Public Health 1995;85:1361-5.

9 Burnett RT, Dale RE, Brook JR, et al. Association between ambient carbon monoxide levels and hospitalization for congestive heart failure in the elderly in 10 Canadian cities. Epidemiology 1997;8:162-7.
10 Schwartz J. Air pollution and hospital admissions for cardiovascular disease in Tucson. Epidemiology 1997;8: $371-7$.

11 Burnett R, Cakmak S, Brook J, et al. The role of particulate size and chemistry in the association between summertime ambient air pollution and hospitalization for cardiorespiratory diseases. Environ Health Perspect 1997;105: 614-20.

12 Morris R, Naumova E. Carbon monoxide and hospital admissions for congestive heart failure: evidence of an ncrease effect at low temperatures. Environ Health Perspect 1998;106:649-53.

13 Schwartz J. Air pollution and hospital admissions for heart disease in eight US counties. Epidemiology 1999;10:17-22.

14 Wichmann H, Mueller W, Allhoff P, et al. Health effects during a smog episode in West Germany in 1985. Environ Health Perspect 1989;79:89-99.

15 Pönka A, Virtanen M. Low-level air pollution and hospital admissions for cardiac and cerebrovascular diseases in Helsinki. Am F Public Health 1996;86:1273-80.

16 Poloniecki J, Atkinson R, Ponce de Leon A, et al. Daily time series for cardiovascular hospital admissions and previous day's air pollution in London, UK. Occup Environ Med 1997;54:535-40.

17 Wordley J, Walters S, Ayres J. Short term variations in hospital admissions and mortality and particulate air pollution. pital admissions and mortality and partic

18 Prescott G, Cohen G, Elton R, et al. Urban air pollution and cardiopulmonary ill health. a 14.5 year time series study. Occup Environ Med 1998;55:697-704

19 Morgan G, Corbett S, Wlodarczyk J. Air pollution and hospital admissions in Sydney, Australia, 1990 to 1994. Am f Public Health 1998;88:1761-6.

20 Wong TW, Lau TS, Yu TS, et al. Air pollution and hospital admissions for respiratory and cardiovascular diseases in Hong Kong. Occup Environ Med 1999;56:679-83.

21 Pantazopoulou A, Katsouyanni K, Kourea-Kremastinou J, et al. Short-term effects of air pollution on hospital emergency outpatient visits and admissions in the greater athens, Greece Area. Environ Res 1995;69:31-6.

22 Katsouyanni K, Pantazopoulou A, Touloumi G, et al. Evidence for interaction between air pollution and high temperature in the causation of excess mortality. Arch Environ Health 1993;48:235-42.

23 Katsouyanni K, Zmirou D, Spix C, et al. Short-term effects of air pollution on health: a European approach using epidemiological time-series data. The APHEA project: background, objectives, design. Eur Respir f 1995;8: 1030-8.

24 Schwartz J, Spix C, Touloumi G, et al. Methodological issues in studies of air pollution and daily counts of deaths or hospital admissions. 7 Epidemiol Community Health 1996;50 (suppl 1):S3-11.

25 Katsouyanni K, Schwartz J, Spix C, et al. Short term effects of air pollution on health: a European approach using epidemiologic time series data: the APHEA protocol. F Epidemiol Community Health 1996;50 (suppl 1): S12-18.

26 Ballester F, Sáez M, Alonso E, et al. El proyecto EMECAM: Estudio español sobre la relación entre la contaminación atmosferica y la mortalidad. Antecedentes, participantes, objetivos, material y métodos. Rev Esp Salud Pública 1999; 73:165-75.

27 Pérez Hoyos S, Sáez M, Barceló M, et al. Protocolo EMECAM: Análisis del efecto a corto plazo de la contaminación atmosférica sobre la mortalidad. Rev Esp Salud Pública 1998;73:177-85.

28 Council Directive 1999/30/EC of 22 April 1999 relating to limit values for sulphur dioxide, nitrogen dioxide and oxides of nitrogen, particulate matter and lead in ambient air. Official fournal of the European Communities L163, 41-60; 6-29-1999.

29 Ballester F, Corella D, Pérez Hoyos S, et al. Air pollution and mortality in Valencia, Spain: a study using the APHEA methodology. F Epidemiol Community Health 1996;50:52733.

30 Tenías J, Pérez Hoyos S, Molina R, et al. Efectos a corto plazo entre contaminación atmosférica y mortalidad. Resultados del Proyecto EMECAM en la ciudad de Valencia. Rev Esp Salud Pública 1999;73:267-74.

31 Sunyer J, Castellsague J, Sáez M, et al. Air pollution and mortality in Barcelona. I Epidemiol Community Health 1996;50 (suppl 1):S76-80

32 Michelozzi P, Forastiere F, Fusco D, et al. Air pollution and daily mortality in Rome, Italy. Occup Environ Med 1998;55: $605-10$.

33 Katsouyanni K. Health effects of air pollution in southern Europe: are there interacting factors? Environ Health Perspect 1995;103 (suppl 2):23-7.

34 Castellsague J, Sunyer J, Sáez M, et al. Short-term ssociation between air pollution and emergency room visits for asthma in Barcelona. Thorax 1995;50:1051-6.

35 Stieb D, Burnett R, Beveridge R, et al. Association between ozone and asthma emergency department visits in Saint John, New Brunswick, Canada. Environ Health Perspect 1996;104:1354-60.

36 Anderson HR, Spix C, Medina S, et al. Air pollution and daily admissions for chronic obstructive pulmonary disease Respir f 1997;10:1064-71.

37 Tenías J, Ballester F, Rivera M. Association between hospital emergency visits for asthma and air pollution in Valencia, Spain. Occup Environ Med 1998;55:541-7. 
38 Tenías J, Ballester F, Rivera M, et al. Efecto a corto plazo de la contaminación atmosférica sobre las urgencias hospitalarias por enfermedad pulmonar obstructiva crónica en la ciudad de Valencia. [Abstract]. Gac Sani

39 United Nations Economic Comission for Europe. World Health Organization. Health effects of ozone and nitrogen oxides in an integrated assesessment of air pollution. Leicester: Institute for Environment and Health, 1997.

40 Peters A, Döring A, Wichmann H, et al. Increased plasma viscosity during an air pollution episode: a link to mortality? Lancet 1997;349:1582-7.

41 Pope C, Dockery D, Kanner R, et al. Oxigen saturation, pulse rate, and particulate air pollution. Am F Respir Crit Care Med 1999;159:365-72.

42 Gordon T, Nadziejko C, Schlesinger R, et al. Pulmonary and cardiovascular effects of acute exposure to concentrated ambient particulate matter in rats. Toxicol Lett 1999;96-97: 285-8

43 Goldeski J, Sioutas C, Verrier R, et al. Inhalation exposure of canines to concentrated ambient air particles. Am f Respir Crit Care Med 1997;155:A246-6.
44 Ström J, Alfredsson L, Malmfors T. Carbon monoxide: causation and aggravation of cardiovascular diseases - a review of the epidemiologic and toxicologic literature. Indoor

45 Stern F, Halperin W, Hornung R, et al. Heart diseade mortality among bridge and tunnel officers exposed to carbon monoxide. Am F Epidemiol 1988;128:1276-88.

46 Allred E, Bleecker E, Chaitman B, et al. Short-term effects of carbon monoxide exposure on the exercise performange of subjects with coronary artery disease. $N$ Engl f Med 1989;23:1426-32.

47 Allred E, Bleecker E, Chaitman B, et al. Effects of carbon monoxide on myocardial ischemia. Environ Health Perspect 1991;91:89-132.

48 Librero J, Ordiñana R, Peiró S. Análisis automatizado de la calidad del conjunto mínimo de datos básicos. Implicaciones para los sistemas de ajuste de riesgos. Gac Sanit 1998;12:9-21.

49 Stieb D, Beveridge R, Rowe B, et al. Assessing diagnostic classification in an emergency departament: implications for daily time series studies of air pollution. Am. F Epidemiol. 1998;148:666-70. 